$10^{6} / \mathrm{ml}$ thì không có trường hợp nào có thai ${ }^{5}$.

Trong nghiên cứu của chúng tôi, không có trường hợp nào có thai khi mật độ tinh trùng sau lọc rửa $\leq 10.10^{6} / \mathrm{ml}$. Theo Bùi Thị Thanh Tuyên (2016), không có trường hợp nào có thai khi mât độ tinh trùng trước lọcrửa $<10.10^{6} / \mathrm{ml}$ và không có trường hợp nào có thai khi mật độ tinh trùng sau loc rửa $<30.10^{6} / \mathrm{ml}^{6}$. Không có trường hợp nào có thai khi catheter có máu.

\section{KẾT LUÂ̂N}

- Tỷ lệ có thai lâm sàng là $16.4 \%$, thai phát triển trong buồng tử cung và có tim thai là $14.8 \%$, thai ngừng phát triển $1.2 \%$ và chửa ngoài tử cung $0.4 \%$.

- Các yễu tố liên quan đến tỷ lệ có thai lâm sàng: tuổi vợ trẻ, thời gian vô sinh $\leq 4$ năm, số nang noãn $\geq 2$, độ dày niêm mạc tử cung $\geq 8 \mathrm{~mm}$, mật độ và tổng tinh trùng di động tiến tới trước lọc rửa $\geq 20.10^{6} / \mathrm{ml}$; mật độ sau lọc rửa $>10.10^{6} / \mathrm{ml}$ và kỹ thuật bơm catheter không có máu.

\section{TÀI LIÊU THAM KHẢO}

1. Lê Thị Minh Nguyệt. Mối liên quan một số chỉ số tinh dịch đồ theo WiHO 2010 và tỳ lệ có thai trong điều trị vô sinh bằng bơm tinh trùng vào buồng tử cung tai Bênh viên Phu sản Trung ương từ tháng 10/2015 đến tháng 03/2016 [Luận văn thạc sỹ Y học], Trường Đại học Y Hà Nội; 2016.

2. Hoàng Thị Phương Thủy. Nghiên cứu một số yếu tô liên quan và kết quả của phương pháp bơm tinh trùng vào buồng tử cung tại Bệnh viện phu sản Trung ương năm 2016 [Luận văn bác sỹ் chuyên khoa cấp II], Trường Đại học Y Hà Nội; 2017.

3. Vargas-Tominaga $L$, Alarcón $F$, Vargas $A$, Bernal G, Medina A, Polo Z. Associated factors to pregnancy in intrauterine insemination. JBRA assisted reproduction. 2020;24(1):66-69.

4. Nguyê̂n Hoàng Hà. Đánh gia kết quả bước đâu của phương pháp bơm tinh trùng vào buông tử cung tại Bệnh viện Sản Nhi Vính Phúc từ 06/2013 06/2017 [Luâân văn bác sĩ chuyên khoa cấp II] Trường Đại học Y Hà Nội; 2017.

5. Hồ Sỹ Hừng, Nguyến Viêt Quang. Khuyến cáo ngưỡng các chỉ số tinh dịch đô để chỉ định bơm tinh trưng vào buồng tử cung. Chuyên đề hố trợ sinh sản - vô sinh sản phụ khoa, Hội nghị Sản phụ khoa Việt- Pháp;2011.

6. Bùi Thì Thanh Tuyền. Nghiên cứu mối liên quan giữa số lượng, chất lượng tinh trùng trước và sau loc rửa với tỳ lệ có thài của kĩ thuật IUI tại Bệnh viện Trường Đại học Y Hà Nôi [Luận văn thạc sĩ y học], Trường Đại học Y Hà Nội; 2016.

\title{
ĐÁNH GIÁ KẾT QUẢ BƯớC ĐẦU ĐIỀU TRI PHÁC Đồ GEMCITABINE KÊTT HỢP CISPLATIN TRONG UNG THƯ ĐƯờnG MẬT GIAI ĐOẠN MUỘN
}

\section{TÓM TẮT}

Muc tiêu nghiên cứu: Đánh giá kết quả bước đầu điều trị và độc tínhphác đồ gemcitabine kết hợp cisplatin trong điểu trị bệnh nhân ung thư biểu mô đường mất giai đoạn muộn tại bệnh viện K năm 20152020. Đối tướng và phưởng pháp nghiên cứu: Nghiên cứu mồ tả cắt ngang, hồi cứu kết hợp tiến cứu trên 55 bệnh nhân ung thư biểu mô đường mật giai đoạn muộn được điều trị hóa chất phác đồ gemcitabine - cisplatin tai bẹnh viên $K$ từ $1 / 2015$ đến hết tháng 12/2020. Kết quả: Tỷ lệ kiểm soát triệu chứng cơ năng là $63,7 \%$. Tỷ lệ kiểm soát bệnh là $67,4 \%$, trong đó có $5,5 \%$ đáp ứng hoàn toàn, đáp ứng một phẩn chiếm $27,3 \%$, bệnh ổn định $34,6 \%$. Độc tính trên hệ tạo huyết: Giảm hồng câu độ 3,4 lần lượt là 3,2 và $1,3 \%$, giảm bạch câu trung tính dộ 3,4 là 7,2 và $5,9 \%$. Các độc tính trên gan thận chủ yếu gặp độ 1 , độ 2 . Kết luận: Gemcitabine - cisplatin là phác đồ hiệu quả trong điêu trị ung thư biểu mô

${ }^{1}$ Trường Đại hoc Y Hà Nọi

Chịu trách nhiệm chính: Ninh Thị Thảo

Email: ninhthaont@gmail.com

Ngày nhận bài: 23.6.2021

Ngày phản biên khoa hoc: 18.8.2021

Ngày duyệt bài: 24.8.2021
Nịnh Thị Thảo ${ }^{1}$, Vũ Hồng Thăng ${ }^{1}$

đường mật giai đoạn muộn.

Tì̛ khóa: Ung thư biểu mô đường mật, giai đoạn muộn, gemcitabine - cisplatin, độc tính.

\section{SUMMARY \\ EARLY EFFECTIVENESS OF GEMCITABINE \\ PLUS CISPLATIN CHEMOTHERAPY IN TREATMENT OF ADVANCED CHOLANGIOCARCINOMA}

Objective: To evaluate the early efficacy and safety profile of gemcitabine plus cisplatin chemotherapy in patients with advanced cholangiocarcinoma. Patients and method: Restropective and prospective description study of 55 patients with advanced cholangiocarcinoma who received gemcitabine plus cisplatin chemotherapy. Results: Rate of control physical symptoms is $63,7 \%$. Disease Control Rate (DCR) is 67,4\%. There was 5,5\% case with complete respond. The partly respond is $57,9 \%$. The incidence of erythrocytopenia in grade 3 and 4 is respectively $3,2 \%$ and $1,3 \%$. Leukopenia in grade 3 and grade 4 is $7,2 \%$ and $5,9 \%$. Liver and kidney toxicity is in grade 1 and grade 2 . Conclusions: Gemcitabine plus cisplatin is an effective chemotherapeutic regimen for advanced cholangiocarcinoma in patients. 
Keywords: advanced cholangiocarcinoma, gemcitabine - cisplatin, toxicity.

\section{I. ĐẶT VẤN ĐỀ}

Ung thư đường mật là bệnh lý ác tính của các tế bào biểu mô hệ thống đường mật từ trong gan đến ngoài gan[1]. Ung thư đường mật là bệnh hiếm gặp và thường phát hiện ở giai đoạn muộn[2]. Có tới $70-80 \%$ bệnh nhân đến viện không có khả năng phẫu thuật triệt căn[3].

Điều trị ung thư đường mật giai đoạn muộn còn nhiều khó khăn và thách thức, phần lớn $\mathrm{BN}$ chỉ điều trị triệu chứng[4]. Điều trị hóa chất cho bệnh nhân ung thư đường mật giai đoạn muộn là điều trị chủ yếu, kết hợp với điêuu trị chăm sóc giảm nhẹ. Phác đồ hóa chất dựa trên nền tảng gemcitabine được xem là phác đồ đem lại hiệu quả, nhằm giảm nhe triệu chứng và kéo dài thời gian sống thêm cho bệnh nhân[5]. Phác đồ gemcitabine kết hợp cisplatin được ưu tiên trong điều trị ung thư đường mật giai đoạn muộn do cho kết quả tốt hơn về sống thêm.

Cho tới nay còn ít nghiên cứu trong nước đánh giá về hiệu quả cũng như mức độ an toàn của phác đồ gemcitabine - cisplatin trong điều trị ung thư biểu mô đường mật giai đoạn muộn. Vì vậy, chúng tôi tiến hành nghiên cứu này với mục tiêu: "Đánh giá kết quả bước đầu điều trị và độc tính phác đồ gemcitabine - cisplatintrong điều trị ung thư biểu mô đường mật giai đoạn muộn tại bệnh viện K 2015-2020".

\section{II. ĐỐI TƯợNG VÀ PHƯƠNG PHÁP NGHIÊN CỨU}

2.1. Thời gian và địa điểm: Chọn các bệnh nhân được điêu trị từ $1 / 2015$ đến hết tháng 12/2020 tai Bênh viện $K$ cơ sở Tân Triều.

\section{2. Đối tượng nghiên cứu}

2.2.1. Tiêu chuẩn chọn bệnh nhân nghiên cứu:

- Chẩn đoán mô bệnh học là ung thư biểu mô đường mật

- Không còn khả năng phẫu thuật triệt căn

- Được điều trị hóa chất ít nhất từ 3 đợt trở lên phác đồ hóa chất gemcitabine - cisplatin

- EGOG 0,1

- Không bị các bệnh mạn tính ảnh hưởng đến thời gian sống thêm và điều trị hóa chất.

- Chức năng gan, thận trong giới hạn bình thường.

- Chấp nhận tham gia nghiên cứu và có hồ sơ theo dõi.

\subsubsection{Tiêu chuẩn loại trừ:}

- Không có chẩn đoán mô bệnh học là ung thư biểu mô đường mật

- Không có thông tin theo dõi điều trị.
- Bệnh nhân bỏ điều trị

- Bệnh nhân tử vong do nguyên nhân khác.

2.3. Cỡ mẫu: cõ̃ mẫu được xác định bằng công thức áp dụng cho nghiên cứu ngang mô tả với tî lệ đáp ứng của phác đồ gemcitabine cisplatin là $0,5[6]$, độ chính xác mong muốn là 0,2,95\% khoảng tin cậy.

2.4. Phương pháp nghiên cứu: mô tả cắt ngang, hồi cứu kết hợp với tiến cứu.

\subsection{Cách thức tiến hành:} án

- Thu thập hồ sơ bệnh án theo mẫu bệnh

- Chọn bệnh nhân đủ tiêu chuẩn vào nghiên cứu

- Ghi nhận các triệu chứng lâm sàng và cận lâm sàng trước khi điều trị.

- Đánh giá bệnh nhân sau 2-3 đợt

- Đánh giá đáp ứng: theo RECIST và đánh giá độc tính theo tiêu chuẩn của Tổ chức $Y$ tế thế giới (WHO).

2.6. Phân tích số liệu: số liệu được nhập và phân tích sử dụng phần mềm SPSS 21.0. Các chì tiêu nghiên cứu bao gồm:

- Tỷ lệ đáp ứng: Hoàn toàn, một phần, giữ nguyên, tiến triển

- Các độc tính trên hệ tạo huyết và chức năng gan thận

\section{7. Đạo đức nghiên cứu:}

- Phác đồ nghiên cứu đã được áp dụng điều trị ở nhiều nước trên thế giới.

- Có sự cho phép của bệnh viện.

- Có sự đồng ý hợp tác của bệnh nhân.

\section{KẾT QUẢ NGHIÊN CỨU}

3.1 Đặc điểm đối tượng nghiên cứu. Tuổi trung bình của bệnh nhẩn là 53,2 tuổi. Bệnh nhân cao tuổi nhất là 76 tuổi, trẻ nhất là 37 tuổi, nhóm tuổi 51-70 tuổi chiếm tỉ lệ cao nhất (73.5\%). Tî lệ nam/ nữ là 1,15/1. Có 15,8\% bệnh nhân có tiền sử sỏi mật. $26,7 \%$ bệnh nhân có xét nghiệm HbsAg dương tính.

Bảng 1: Các triệu chứng lâm sàng

\begin{tabular}{|c|c|c|}
\hline Triệu chứng lâm sàng & Số BN & Tỷ lệ \% \\
\hline Đau bụng & 47 & 85,5 \\
\hline Mệt mỏi chán ăn & 36 & 65,5 \\
\hline Sút cân & 32 & 58,1 \\
\hline Vàng da & 18 & 32,7 \\
\hline Cố chướng & 5 & 9,1 \\
\hline Hạch thượng đòn & 0 & 0 \\
\hline
\end{tabular}

Nhận xét: Đau bụng, chán ăn và sút cân là các triệu chứng hay gặp nhất với tỉ lệ trên $50 \%$. Vàng da không phải là triệu chứng thường gặp với tî lệ 32,7\%. Có 5 trường hợp có dịch ổ bụng trên lâm sàng với tỉ lệ 9,1\%. Không ghi nhận 
trường hợp nào có hạch thượng đòn.

Bảng 2: Vị trí ung thư đường mật.

\begin{tabular}{|c|c|c|}
\hline Vị trí & $\begin{array}{c}\text { Số } \\
\text { BN }\end{array}$ & $\begin{array}{c}\text { Tỷ lệ } \\
\text { \%o }\end{array}$ \\
\hline Ung thư đường mật rốn gan & 37 & 67,3 \\
\hline Ung thư đường mật ngoài gan & 11 & 20 \\
\hline Ung thư đường mật trong gan & 7 & 12,7 \\
\hline
\end{tabular}

Nhận xét: Ung thư đường mật rốn gan gặp chủ yếu chiếm $67,3 \%$. Ung thứ đường mật ngoài gan gặp ở $20 \%$ các trường hợp. Ung thư đường mật trong gan hiếm gặp, chỉ có 7 trường hợp chiếm $12,7 \%$.

\section{2. Đánh giá đáp ứng.}

Bảng 3: Hiệu quả kiểm soát các triệu chứng cơnăng

\begin{tabular}{|c|c|c|}
\hline Đáp ứng cơ năng & $\mathbf{N}$ & Tỷ lệ $\%$ \\
\hline Đáp ứng một phần & 35 & 63,7 \\
\hline Không đáp ứng & 20 & 36,3 \\
\hline Tống & $\mathbf{5 5}$ & $\mathbf{1 0 0}$ \\
\hline
\end{tabular}

Nhận xét: Tỉ lệ bệnh nhân kiểm soát được các triệu chứng cơ năng đạt $63,7 \%$. Ngược lại có 36,3\% bệnh nhân không đáp ứng, xuất hiện các triệu chứng cơ năng nặng lên hoặc xuất hiện các triệu chứng mới.

Bảng 4: Đánh giá tình trạng đáp ứng theo RECIST

\begin{tabular}{|c|c|c|c|c|c|}
\hline \multirow{3}{*}{$\begin{array}{l}\text { Nộf } \\
\text { dung } \\
\text { Số } \\
\text { Lượng }\end{array}$} & \multicolumn{3}{|c|}{ Kiếm soát bệnh } & \multirow{3}{*}{$\begin{array}{l}\text { Bênhh } \\
\text { tîến } \\
\text { triển }\end{array}$} & \multirow{3}{*}{ Tổng } \\
\hline & \multicolumn{2}{|c|}{$\begin{array}{l}\text { Đáp ứng } \\
\text { điêuu trị }\end{array}$} & \multirow{2}{*}{$\begin{array}{l}\text { Bệnh } \\
\text { ổn } \\
\text { định }\end{array}$} & & \\
\hline & $\begin{array}{l}\text { Hoàn } \\
\text { toàn }\end{array}$ & 1 phân & & & \\
\hline $\mathbf{N}$ & 3 & 15 & 19 & 18 & 55 \\
\hline$\%$ & 5,5 & 27,3 & 34,6 & 32,6 & 100 \\
\hline
\end{tabular}

Nhận xét: Tỉ lệ kiểm soát được bệnh chiếm $67,4 \%$ trong đó có 3 trường hợp đáp ứng hoàn toàn chiếm $5,5 \%, 27,3 \%$ đáp ứng một phần, 34,6\% bệnh nhân đat bệnh ổn định. 18 bệnh nhân có bệnh tiến triển chiếm tỉ lệ $32,6 \%$.

\subsection{Tác dụng phụ của hóa chất}

- Trên hệ tạo huyết: Hay gặp nhất là độc tính lên dòng hồng cầu, chiếm $57,1 \%$. Tuy nhiền chỉ là độc tính độ I và dộ II, độ IV chỉ găp ở 1,3\%. Độc tính hạ bạch cầu trung tính gặp ở $39 \%$, chủ yếu là độc tính độ I và II. Hạ bạch cầu độ IV chỉ gặp ở 5,9\%.

- Độc tính lên gan, thận ít gặp, chủ yếu là độc tính độ I và II, độc tính độ IV đều gặp dưới $5 \%$.

\section{BÀN LUÂNN}

Tuổi trung bình của bệnh nhân trong nghiên cứu của chúng tôi là 53,2 tuổi, kết quả này tương đương với Nguyễn Thị Bích Phượng (2015) là 54,5 [5]. Tuy nhiên kết quả này thấp hơn kết quả của một số tác giả nước ngoài. Theo
T Okusaka và CS (2010) độ tuổi trung bình là 65[6]. Theo nghiên cứu $A B C-02$, tác giả J.Dierks và CS (2017), tuổi trung bình là 63[7].

Về triệu chứng lâm sàng, đau bụng, chán ăn và sút cân là các triệu chứng hay gặp nhất với tỉ lệ lần lượt là $85,5 \%, 65,5 \%$ và $58.1 \%$. Vàng da không phải là triệu chứng thường gặp với tỉ lệ $32,7 \%$. Ghi nhận có 5 trường hợp có dịch ổ bụng trên lâm sàng. Theo Nguyền Thị Bích Phượng (2015), kết quả tương tự.

Về đáp ứng điều trị, tỉ lệ bệnh nhân thuyên giảm triệu chứng cơ năng là $67,3 \%$, kết quả này cao hơn với kết quả của các nghiên cứu trên nhóm đối tượng bệnh nhân ung thư đường mật giai đoạn muộn, nhưng tiến hành điều trị bằng các phác đồ hóa chất gemcitabine đơn thuân. Nguyễn Thị Bích Phượng (2015) cho biết đáp ứng cơ năng là $63,1 \%[5]$. Về đáp ứng thực thể, tỷ lệ kiểm soát bệnh trong nghiên cứu của chúng tôi là $67,4 \%$. Nghiên cứu của chúng tôi cho thây tỷ lệ kiểm soát bệnh cao hơn của Nguyễn Thị Bích Phượng(2015)-63,3\%[5]. Theo T Okusaka và CS (2010), tỷ lệ kiểm soát bệnh là $68,3 \%$ [6]. Theo Juan Valle và CS (2010), tỷ lệ kiểm soát bệnh là $81,4 \%$ [8]. Kết quả nghiển cứu của chúng tôi tương tự của các tác giả nước ngoài.

Về tác dụng trên hệ tạo huyết, kết quả nghiên cứu của chúng tôi cho thây hầu hết các tác dụng phu đều ở mức đô nhe và không ảnh hưởng đến liệu trình và liều điểu trị cho bệnh nhân. Thiếu máu là độc tính hay gặp, chiếm $57,1 \%$ trong đó thiếu máu độ 4 chiếm $1,3 \%$. Ha bạch câu gặp ở $26,7 \%$ trong đó hạ bạch câu độ 3,4 chiếm $8,5 \%$. Ha bạch cầu trung tính gặp ở $39 \%$,trong đó hạ bạch cầu trung tính độ4 chiếm 5,9\%. Tác giả Nguyễn Thị Bích Phượng (2015) cũng cho kết quả nghiên cứu tương tự. Theo $T$ Okusaka và CS (2010), tỷ lệ hạ bạch cầu độ 3, 4 là $7,8 \%$, hạ bạch câu trung tính độ 4 là $5,1 \%$, thiếu máu độ 4 là 1,6\%[6]. Kết quả nghiên cứu củaJ.Dierks và CS (2017), tỷ lệ hạ bạch cầu trung tính độ 4 là $6,2 \%$, thiếu máu độ 4 là 1,4\%[7]. Nhìn chung, tỷ lệ gặp tác dụng phụ trên hệ tạo huyết trong nghiên cứu của chúng tổi thường thấp và tương tự như kết quả của các nghiên cứu nước ngoài. Một số tác dụng phụ ngoài hệ tạo huyết đều ở mức độ nhẹ, chủ yếu độ 1 và độ 2 , có thể kiểm soát được bằng các thuốc hỗ trợ khi điều trị ung thư.

\section{KẾT LUẬN}

Phác đồ gemcitabine - cisplatin áp dụng cho các các bệnh nhân ung thư đường mật giai đoạn muộn trong nghiên cứu này đem lại hiệu quả 
kiểm soát bệnh đáng kể. Cụ thể là:

- 63,7\% bệnh nhân kiểm soát được các triệu chứng cơ năng.

- Đánh giá đáp ứng theo RECIST, tỉ lê kiểm soát được bệnh chiếm $67,4 \%$ trong đó $5,5 \%$ đáp ứng hoàn toàn, $27,3 \%$ đáp ứng một phần, 34,6\% bênh nhân đạt bênh ổn định

- Tác dụng phụ trên hệ tạo huyết: Giảm hồng cầuđộ 4 chỉ chiếm 1,3\%. Giảm bạch cầu trung tính độ 4 là 5,9\%. Độc tính trên gan, thận ít gặp, chủ yếu là độ 1 và độ 2 .

\section{TÀl LIỆ THAM KHẢO}

1. Trần Đình Thơ và CS (2005), Một số đặc điểm dịch tể học của ung thư đường mật, $Y$ học Việt Nam. tháng 5, tâp 310, tr.120-126.

2. Nguyễn Quang Nghĩa, Đoàn Thanh Tùng, Nguyễn Tiến Quyết, (2004), Chẩn đoán và kết quả điêu trị phẫu thuật ung thư đường mật trong gan, Y hoc Viêt Nam. 304, tr.149-159.

3. Đoàn Thanh Tùng, Nguyền Quang Nghĩa, Nguyễn Tiến Quyêt (2005), Nghiên cứu các yếu tố ảnh hưởng đến thời gian sống sau phẫu thuật bênh nhân ung thư đường mật trong gan, $Y$ học Viêtt Nam Số đặc biêtt tháng 5, tr.110-119.

4. Nguyển Tiến Quyêt (2005), Kết quả điều trị ung thư đường mật ngoài gan, Tạp chí Y Học Việt Nam. 310, tr.5.

5. Nguyển Thị Bích Phương, "Đánh giá kết quả điêu trị hóa chất bênh nhân ung thư đường mât không còn khả năng phẫu thuật", luận vằn tốt nghiếp bác sỹ nội trú chuyên ngành ung thư 2015

6. T. Okusaka et al (2010), Gemcitabine alone or in combination with cisplatin in patients with biliary tract cancer: a comparative multicentre study in Japan, Br J Cancer. 103(4), tr. 469-74.

7. J.Dierks et al (2017), Effective treatment of advanced biliary tract carcinoma using 5fluorouracil continuous infusion with cisplatin, Ann Oncol. 9(6), tr. 653

8. J. W. Valle et al (2009), Gemcitabine alone or in combination with cisplatin in patients with advanced or metastatic cholangiocarcinomas or other biliary tract tumours: a multicentre randomised phase II study - The UK ABC-01 Study, Br J Cancer. 101(4), tr. 621-7.

\section{ĐÁNH GIÁ KẾT QUẢ HÓA TRI BỔ TRỢ PHÁC ĐỒ FOLFOX4 TRONG ĐIỀU TRI UNG THƯ ĐẠI TRÀNG TẠI BỆNH VIỆN THANH NHÀN}

\section{TÓM TẮT}

Mục tiêu: Đánh giá kết quả và tác dụng không mong muốn của phác đồ FOLFOX4 trong điều trị bổ trơ ung thư đại tràng (UTĐT) tai bệnh viện Thanh Nhàn. Đối tượng và phương pháp nghiên cứu: Mô tả hồi cứu trển 43 bệnh nhân UTĐT đã được phẫu thuât triêt căn, xếp giai đoạn II nguy cơ cao và giai đoạn III được hóa trị bổ trơ phác đồ FOLFOX4 tại bệnh viện Thanh Nhàn từ tháng $1 / 2015$ đến tháng 12/2018. Kết quả: Tỷ lệ sống thêm không bệnh 3 năm là $79,1 \%$, tỷ lệ sông thêm toàn bộ là $88,4 \%$. Tác dụng không mong muốn thường ở mức độ $1-2$, chỉ $14,0 \%$ đôc tính ở đô 3-4, tác dung phu có thể kiểm soát được. Kết luận: Phác đồ FOLFOX4 có hiệu quả điều trị cao và độc tính có thể kiểm soát được trong điều trị bổ trợ UTĐT.

Tư khóa: FOLFOX4, đại tràng, hiệu quả và an toàn

\section{SUMMARY}

\section{EVALUATION OF THE RESULTS OF ADJUVANT CHEMOTHERAPY WITH FOLFOX4 REGIMEN IN COLON CANCER}

\footnotetext{
${ }^{1}$ Bệnh viện Thanh Nhàn

ª̂̀nh viền $K$

Chịu trách nhiệm chính: Bùi Thị Phương Thu

Email: Thuphuongbui.tb@gmail.com

Ngày nhận bài: 21.6.2021

Ngày phản biên khoa hoc: 17.8.2021

Ngày duyệt bài: 23.8.2021
}

\section{Bùi Thị Phương Thu ${ }^{1}$, Đỗ Huyền Nga ${ }^{2}$}

\section{AT THANH NHAN HOSPITAL}

Objectives:To evaluate the results and the sideeffects of the FOLFOX4 regimen in adjuvant treatment of the colon cancer at Thanh Nhan hospital.Objects and methods: Retrospective description of 43 adenocarcinoma colorectal cancer patients were treated with FOLFOX4 regimen at Thanh Nhan hospital from January2015 to December 2018. Results:the 3years disease-free survival (DFS) was $79,1 \%$, the overall survival (OS) was $88,4 \%$. The side-effects were general at thegrade of $1-2$, while there was only $14,0 \%$ at the grade of $3-4$. The side-effects were manageable. Conclusion:The FOLFOX4 regimen in adjuvant chemotherapy was highly effective in the colon cancer treatment. The side-effects were manageable during the treatment process using FOLFOX regimen.

Key word. FOLFOX4, colorectal, efficacy and safety.

\section{I. Đă̆T VẤN ĐỀ}

Ung thư đại tràng (UTĐT) là một bệnh hay gặp ở các nước phát triển, và đang có xu hướng tăng lên ở các nước đang phát triển. Tại Việt Nam ước tính năm 2020 trên cả nước có khoảng 6.448 người mới mắc đứng hàng thứ 5 ở cả hai giới, trong đó tỷ lệ mắc của nam đứng thứ 4 và nữ đứng hàng thứ $3^{1}$. Trên thế giới, nhiều nghiên cứu và thử nghiêm lâm sàng chứng minh được lợi ích của hóa trị bổ trợ sau phẫu thuật đối với UTĐT giai đoạn II nguy cơ cao và giai đoạn 